\title{
O PRINCÍPIO DA SUBSIDIARIEDADE E SUA APLICAÇÃO NO DIREITO AMBIENTAL BRASILEIRO / THE PRINCIPLE OF SUBSIDIARITY AND ITS APPLICATION IN BRAZILIAN ENVIRONMENTAL LAW
}

\author{
Vítor Pimentel Pereira ${ }^{1}$
}

\section{Resumo}

Neste artigo, será apresentada uma investigação a respeito da gênese e fundamentos do princípio da subsidiariedade, de sua presença nos sistemas constitucionais federativos e de seus critérios de aplicação.

Após estas considerações prévias, perquirir-se-á sobre a possibilidade de sua existência e efetivação em um ramo jurídico muito peculiar: o direito ambiental.

Por fim, haverá uma análise do ordenamento legal brasileiro, abordando a aplicabilidade da subsidiariedade nas matérias de repartição de competências, gestão ambiental e na debatida questão do licenciamento ambiental.

Palavras-chave: Princípio da subsidiariedade. Direito ambiental. Subsidiariedade na repartição de competências. Subsidiariedade na gestão ambiental e no licenciamento ambiental.

\begin{abstract}
In this article, an investigation will be presented regarding the genesis and rationale of the principle of subsidiarity, his presence in the federal constitutional systems and their application criteria.

After these preliminary considerations, will to assert itself on the possibility of its existence and effectiveness in a very peculiar legal system: environmental law.

Finally, there will be an analysis of the Brazilian legal system, addressing the applicability of subsidiarity in matters of division of competences, environmental management and debated issue of environmental licensing
\end{abstract}

Keywords: Principle of subsidiarity. Environmental law. Subsidiarity in the division of competences. Subsidiarity in environmental management and environmental licensing.

\footnotetext{
${ }^{1}$ Para um interessante resumo do princípio da subsidiariedade assim como entendido pela Igreja, ver PONTIFÍCIO CONSELHO JUSTIÇA E PAZ. Compêndio da doutrina social da Igreja. Tradução da CNBB. São Paulo: Paulinas, 2005. p. 111-113; LANGLOIS, José Miguel Ibañes. Doutrina social da Igreja. Lisboa: Rei dos Livros, 1990.
}

* Mestre em Direito pela Faculdade de Direito da Universidade do Estado do Rio de Janeiro UERJ. Advogado. Especialista em Regulação de Petróleo e Derivados, Álcool Combustível e Gás Natural da Agência Nacional do Petróleo, Gás Natural e Combustíveis (ANP). 


\section{INTRODUÇÃO}

A existência do princípio da subsidiariedade é tema ainda pouco explorado em plagas nacionais. Contudo, sua consagração no âmbito da Ciência Política e sua positivação no interior do Tratado da União Européia suscitam uma provocação sobre a possibilidade de sua presença e aplicação no campo jurídico.

Neste artigo, será apresentada uma investigação a respeito da gênese e fundamentos deste princípio, de sua presença nos sistemas constitucionais federativos e de seus critérios de aplicação. Após estas considerações prévias, perquirir-se-á sobre a possibilidade de sua existência e efetivação em um ramo jurídico muito peculiar: o direito ambiental. Por fim, haverá uma análise do ordenamento e sistemática legal brasileiros, abordando a aplicabilidade da subsidiariedade nas matérias de repartição de competências, gestão ambiental e na debatida questão do licenciamento ambiental.

\section{GÊNESE E FUNDAMENTOS DO PRINCÍPIO DA SUBSIDIARIEDADE}

Aponta-se o surgimento do princípio da subsidiariedade no interior do pensamento católico romano ${ }^{1}$ como tentativa de explicar as relações existentes entre os entes que compõem uma sociedade e a forma de controle da ingerência dos vários estratos sociais uns sobre os outros.

Há uma tendência geral em considerar que a elaboração do princípio deu-se por meio da Doutrina Social da Igreja. De fato, Leão XIII, na Encíclica Rerum Novarum, já indica a existência do princípio, ainda que de forma incipiente, sendo freqüente a citação deste como o primeiro sumo pontífice a referir-se à questão da subsidiariedade, ainda que não a denominando expressamente desta forma. Na referida Encíclica, Leão XIII desenvolve 
considerações sobre a independência da família enquanto sociedade doméstica e menor em relação ao Estado. Aduz que a família, a exemplo da sociedade civil,

\begin{abstract}
é uma sociedade propriamente dita, com a sua autoridade e o seu governo paterno, é por isso que sempre indubitavelmente na esfera que lhe determina o seu fim imediato, ela goza, para a escolha e uso de tudo o que exigem a sua conservação e o exercício duma justa independência [...]
\end{abstract}

Querer, pois, que o poder civil invada arbitrariamente o santuário da família, é um erro grave e funesto. Certamente, se existe algures uma família que se encontre numa situação desesperada, e que faça esforços vãos para sair dela, é justo que, em tais extremos, o poder público venha em seu auxílio, porque cada família é um membro da sociedade. Da mesma forma, se existe um lar doméstico que seja teatro de graves violações dos direitos mútuos, que o poder público intervenha para restituir a cada um os seus direitos. Não é isto usurpar as atribuições dos cidadãos, mas fortalecer os seus direitos, protegê-los e defendê-los como convém. Todavia, a ação daqueles que presidem ao governo público não deve ir mais além; a natureza proíbe-lhes ultrapassar esses limites. A autoridade paterna não pode ser abolida, nem absorvida pelo Estado, porque ela tem uma origem comum com a vida humana. ${ }^{2}$

Nestes termos, ainda que com a preocupação voltada para a questão familiar, fica assentada a doutrina da subsidiariedade: o Estado só deve interferir no âmbito da sociedade menor quando ficar demonstrado que aquela sociedade não tem condições de manter-se dignamente ou que ocorre grave violação de direitos fundamentais no interior da mesma (a hipótese, por exemplo, de maus tratos contra crianças no âmbito familiar).

Esta formulação por parte do pontífice parece ter uma origem bastante definida, embora olvidada pela doutrina: o jovem Gioacchino Pecci, futuro Papa Leão XIII, foi aluno de Luigi Taparelli D’Azeglio, jesuíta italiano que esteve entre os primeiros pensadores católicos a formular o princípio da subsidiariedade.

D’Azeglio estrutura a sociedade em três níveis: a protarquia, as deutarquias ou consórcios e os grêmios ou agrupamentos sociais. Estes últimos constituiriam os entes menores de uma sociedade, como as famílias e as cidades. As deutarquias ou consórcios, por sua vez, consubstanciavam as províncias ou estados, enquanto a sociedade maior composta das outras sociedades menores seria a protarquia (o Reino ou República, por exemplo). A partir desta classificação, D’Azeglio enuncia ser uma lei fundamental das relações entre estes entes que o ente superior, ou seja, a protarquia, deva conservar intacto o ser ou existência dos

\footnotetext{
${ }^{2}$ LEÃO XIII. Carta Encíclica Rerum Novarum, de 15 de maio de 1891, nº. 21. In: SECRETARIA GERAL DA PRESIDÊNCIA DA CÂMARA DOS DEPUTADOS (Org.). Documentos pontifícios sobre questões sociais. Brasília: Imprensa Nacional, 1967. p. 15-16.
} 
entes menores e os fins próprios a que estes entes estão ordenados. Todo ente possui fins próprios a serem cumpridos e tais fins devem ser respeitados pelos entes maiores, coadjuvando quando necessário para a manutenção dos fins próprios que representam a perfeição dos entes menores. ${ }^{3}$

Além disso, estabelece que, salvo para assegurar de forma mais efetiva o bem comum, deve haver limites à ação da autoridade superior que venha a obstaculizar a liberdade dos entes menores. E, mesmo nos casos de atuação das ordens emanadas da autoridade superior em nome do bem comum, ou da efetivação de princípios universais, a aplicação individual aos grupos menores faz-se por iniciativa de quem melhor conhece os indivíduos e de quem possui uma relação mais estreita com estes. ${ }^{4} \mathrm{O}$ exemplo formulado é o da comunidade familiar, permitindo-se à autoridade superior nela penetrar apenas por razões acidentais. Eis aí os lineamentos básicos de um princípio de subsidiariedade que, certamente, calaram fundo no espírito do discípulo Gioacchino Pecci, futuramente elevado ao sólio pontifício, demonstrando este, por meio da Rerum Novarum, a conexão entre seu pensamento e aquele de seu antigo mestre.

No âmago da própria Doutrina Social, o fermento do pensamento de Taparelli D’Azeglio e de Leão XIII irá desembocar na Encíclica Quadragesimo Anno de Pio XI, indicada pela doutrina, com bastante razão, como a principal formuladora e sistematizadora do conceito de subsidiariedade. Nas palavras do pontífice:

Verdade é, e a história o demonstra abundantemente, que, devido à mudança de condições, só as grandes sociedades podem hoje levar a efeito o que antes podiam até mesmo as pequenas; permanece contudo imutável aquele solene princípio da filosofia social: assim como é injusto subtrair aos indivíduos o que eles podem efetuar com a própria iniciativa e indústria, para o confiar à coletividade, do mesmo modo passar para uma sociedade maior e mais elevada o que sociedades menores e inferiores podiam conseguir, é uma injustiça, um grave dano e perturbação da boa ordem social. O fim natural da sociedade e da sua ação é coadjuvar os seus membros, não destruí-los nem absorvê-los.

Deixe, pois, a autoridade pública ao cuidado de associações inferiores aqueles negócios de menor importância, que a absorveriam demasiado; poderá então desempenhar mais livre, enérgica e eficazmente o que só a ela compete, porque só ela o pode fazer: dirigir, vigiar, urgir e reprimir, conforme os casos e a necessidade requeiram. Persuadam-se todos os que governam: quanto mais perfeita ordem jerárquica reinar entre as varias agremiações, segundo este princípio da função

\footnotetext{
${ }^{3}$ D’AZEGLIO, Luigi Taparelli. Curso de Direito Natural. Tradução de Pe. Nicolau Rossetti. São Paulo: Anchieta, 1945. p. 232-238.

${ }^{4}$ D’AZEGLIO. Luigi Taparelli. Saggio teoretico di dritto naturale. Livorno: Vincenzo Mansi, 1845. p 253-254.
} 
'subsidiária' dos poderes públicos, tanto maior influência e autoridade terão estes, tanto mais feliz e lisonjeiro será o estado da nação.' (grifo nosso)

Seguindo na mesma linha, encontra-se o Papa João XXIII, na Mater e Magistra, o qual, ao tratar da intervenção do Estado no domínio econômico, acrescenta que, neste campo, deve haver uma atuação subsidiária do Estado capaz de afiançar os direitos essenciais da pessoa humana:

Devemos afirmar desde já que o mundo econômico é criação da iniciativa pessoal dos cidadãos, quer desenvolvam a sua atividade individualmente, quer façam parte de alguma associação destinada a promover interesses comuns.

Mas nele, pelas razões já aduzidas pelos nossos predecessores, devem intervir também os poderes públicos com o fim de promoverem devidamente o acréscimo de produção para o progresso social e em beneficio de todos os cidadãos.

A ação desses poderes, que deve ter caráter de orientação, de estímulo, de coordenação, de suplência e de integração, há de inspirar-se no 'princípio de subsidiariedade', formulado por Pio XI na encíclica Quadragesimo Anno [...]

Mas é preciso reafirmar sempre o princípio que a presença do Estado no campo econômico, por mais ampla e penetrante que seja, não pode ter como meta reduzir cada vez mais a esfera da liberdade na iniciativa pessoal dos cidadãos; mas, deve, pelo contrário, garantir a essa esfera a maior amplidão possível, protegendo efetivamente, em favor de todos e de cada um, os direitos essenciais da pessoa humana. Entre estes há de enumerar-se o direito, que todos têm, de serem e permanecerem normalmente os primeiros responsáveis pela manutenção própria e da família; ora, isso implica que, nos sistemas econômicos, se consinta e facilite o livre exercício das atividades produtivas. ${ }^{6}$

\footnotetext{
${ }^{5}$ PIO XI. Carta Encíclica Quadragesimo Anno, de 15 de maio de 1931, nº 79-80. In: SECRETARIA GERAL DA PRESIDÊNCIA DA CÂMARA DOS DEPUTADOS (Org.). Documentos pontifícios sobre questões sociais. Brasília: Imprensa Nacional, 1967. p. 68. Alteramos a tradução para língua portuguesa. A tradução oficial fala em "princípio da função 'supletiva' dos poderes públicos". Contudo, percebe-se que não houve uma tradução técnica do termo: o original latino fala em "subsidiarii officii principio", ou seja, em princípio da subsidiariedade. A discussão em torno do uso indiscriminado dos termos supletividade e subsidiariedade será feita posteriormente. ${ }^{6}$ JOÃO XXIII. Carta Encíclica Mater et Magistra, de 15 de maio de 1961, nº. 48-52. In: SECRETARIA GERAL DA PRESIDÊNCIA DA CÂMARA DOS DEPUTADOS (Org.). Documentos pontifícios sobre questões sociais. Brasília: Imprensa Nacional, 1967. p. 167-168. Em outra ocasião, na Pacem in Terris, João XXIII retoma o tema da subsidiariedade, mas agora no âmbito da comunidade de Estados: "Como as relações entre os indivíduos, famílias, organizações intermédias e os poderes públicos das respectivas comunidades políticas devem estar reguladas e moderadas, no plano nacional, segundo o princípio de subsidiariedade, assim também, à luz do mesmo princípio, devem disciplinar-se as relações dos poderes públicos de cada comunidade política com os poderes públicos da comunidade mundial. Isto significa que os problemas de conteúdo econômico, social, político ou cultural, a serem enfrentados e resolvidos pelos poderes públicos da comunidade mundial hão de ser da alçada do bem comum universal, isto é serão problemas que pela sua amplidão, complexidade e urgência os poderes públicos de cada comunidade política não estejam em condições de afrontar com esperança de solução positiva." JOÃO XXIII. Carta Encíclica Pacem in Terris, de 11 de abril de 1963, nº. 140. In: SECRETARIA GERAL DA PRESIDÊNCIA DA CÂMARA DOS DEPUTADOS (Org.). Documentos pontifícios sobre questões sociais. Brasília: Imprensa Nacional, 1967. p. 244.
} 
Mais recentemente, seguindo o pensamento de seus antecessores, na Encíclica Centesimus Annus, em comemoração ao centenário da Rerum Novarum, João Paulo II recorda a subsidiariedade:

\begin{abstract}
Assistiu-se, nos últimos anos, a um vasto alargamento dessa esfera de intervenção, o que levou a constituir, de algum modo, um novo tipo de estado, o 'Estado do bemestar'. Esta alteração deu-se em alguns Países, para responder de modo mais adequado a muitas necessidades e carências, dando remédio a formas de pobreza e privação indignas da pessoa humana. Não faltaram, porém, excessos e abusos que provocaram, especialmente nos anos mais recentes, fortes críticas ao Estado do bemestar, qualificado como 'Estado assistencial'. As anomalias e defeitos, no Estado assistencial, derivam de uma inadequada compreensão das suas próprias tarefas. Também neste âmbito, se deve respeitar o princípio de subsidiariedade: uma sociedade de ordem superior não deve interferir na vida interna de uma sociedade de ordem inferior, privando-a das suas competências, mas deve antes apoiá-la em caso de necessidade e ajudá-la a coordenar a sua ação com a das outras componentes sociais, tendo em vista o bem comum. ${ }^{7}$ (grifo do autor)
\end{abstract}

De todo o exposto acima, pode-se haurir os fundamentos para a existência do princípio. O primeiro aspecto é o da proximidade entre aqueles que serão afetados pelas decisões políticas tomadas a seu respeito e os entes incumbidos de tomar estas decisões. Devese buscar a atuação dos entes mais próximos ao cidadão, entes estes sobre os quais o cidadão, por vezes, exerce influência direta (ou indireta, por meio de seus representantes). ${ }^{8}$ Outra perspectiva leva em consideração a efetividade da medida ou decisão no ambiente a que se dirige, buscando-se perceber se um determinado ente possui a capacidade para produzir os efeitos desejados. Por fim, recorde-se o aspecto da descentralização como método de organização e racionalização de distribuição de atribuições entre os vários entes que compõem a sociedade. ${ }^{9}$

\footnotetext{
${ }^{7}$ JOÃO PAULO II. Carta Encíclica Centesimus Annus, de 1 de maio de 1991, nº ${ }^{\circ}$ 48. Disponível em: <http://www.vatican.va/holy_father/john_paul_ii/encyclicals/index_po.htm>. Acesso em: 9 set. 2008.

${ }^{8}$ Correlacionando o conceito de federalismo participativo e a subsidiariedade, cf. ZAMPETTI, Pier Luigi. La familia y el estado social y participativo: un nuevo modelo de desarollo. Buenos Aires: Catálogos, 1997.

${ }^{9}$ No mesmo sentido, analisando o princípio na União Européia, Andrew Jordan: "As conventionally understood, the principle of subsidiarity states that decisions in a political system should be taken at the lowest level consistent with effective action. The Oxford English Dictionary defines it as 'the principle that a central authority should have a subsidiary function, performing only those tasks that cannot be performed effectively at a more immediate or local level.' Subsidiarity therefore provides a strong presumption in favour of decentralisation: it requires that policy functions should not be exercised by the EU unless the EU will be more effective in the operation of policy than Member States acting individually." JORDAN, Andrew. Subsidiarity and environmental policy: which level of government should do what in the European Union? CSERGE Working Paper, 1999. Disponível em: 〈http://www.uea.ac.uk/env/cserge/pub/wp/gec/gec_1999_13.htm>. Acesso em: 9 set. 2008. p. 12.
} 
Depreende-se também de tudo isto que o princípio da subsidiariedade, em sua aplicação, pode ser compreendido sob dois aspectos. Sob um aspecto negativo, funciona como princípio de exclusão da atuação dos entes maiores quando os entes menores puderem atuar eficazmente na gestão de uma determinada matéria. A faceta positiva revela-se na necessidade de atuação do ente maior quando, ao revés, o ente menor não puder realizar com eficácia satisfatória aquela gestão.

\section{A POSITIVAÇÃO DO PRINCÍPIO E SUA EXISTÊNCIA NA FEDERAÇÃO BRASILEIRA}

Não tardou para que o raio de abrangência do princípio fosse ampliado, passando do pensamento católico a ser aplicado no campo jurídico como princípio de repartição de atribuições entre entes estatais, seja no interior de blocos comunitários, seja no interior dos próprios Estados.

Talvez a maior glória do princípio nos últimos anos haja sido sua positivação no âmbito da União Européia. De fato, a subsidiariedade estréia no direito positivo comunitário europeu por meio do Ato Único Europeu (AUE - 1987), precisamente na matéria objeto de exame neste trabalho: o direito ambiental. O art. 25 do AUE introduziu no Tratado da União Européia o art. $1300^{\circ}-\mathrm{R}, \mathrm{n}^{\circ}$. 4, com a seguinte dicção:

A Comunidade intervirá em matéria de ambiente, na medida em que os objectivos referidos no $\mathrm{n}^{\mathrm{o}} .1$ possam ser melhor realizados a nível comunitário do que a nível dos Estados-membros considerados isoladamente. ${ }^{10}$

Em 1992, o princípio da subsidiariedade foi introduzido no Tratado da União Européia (Tratado de Maastricht) por meio do art. $3^{\circ}-\mathrm{B}$, agora não mais limitado à matéria ambiental. $\mathrm{O}$ artigo foi renumerado (atualmente, artigo 5º 3) em 1997 por meio do Tratado de Amsterdã, tendo a presente configuração:

$10 \mathrm{O} \mathrm{n}$. 1 do artigo $1300^{\circ}$ dispunha: "A acção da Comunidade em matéria de ambiente tem por objectivo: preservar, proteger e melhorar a qualidade do ambiente; contribuir para a protecção da saúde das pessoas; assegurar uma utilização prudente e racional dos recursos naturais." 
Art. $5^{\circ}-3$. Em virtude do princípio da subsidiariedade, nos domínios que não sejam da sua competência exclusiva, a União intervém apenas se e na medida em que os objectivos da acção considerada não possam ser suficientemente alcançados pelos Estados-Membros, tanto ao nível central como ao nível regional e local, podendo contudo, devido às dimensões ou aos efeitos da acção considerada, ser mais bem alcançados ao nível da União.

Esta redação atual, não obstante tratar-se de direito estrangeiro, é de suma importância do ponto de vista teórico, vez que dela podem ser extraídos critérios conceituais úteis à aplicação concreta do princípio, conforme se verá a seguir.

Cabe questionar a respeito da existência do princípio numa federação como a brasileira, em virtude da ausência de sua consagração explícita no ordenamento nacional. Em favor de sua existência, embora implícita, sustenta-se que o princípio da subsidiariedade encontra na organização federal seu principal campo de atuação, vez que a presença de um sistema de repartição de competências é essencial à idéia de uma federação. ${ }^{10}$ Como será abordado, a subsidiariedade é um princípio que pode funcionar como instrumento de repartição de atribuições e competências no interior de um Estado. Tratar-se-ia de um princípio estrutural não escrito que informaria o constituinte quando da atribuição de competências aos entes maiores e menores que compõem a federação ${ }^{11}$. Ademais, há uma ingente proximidade entre a autonomia dos entes federativos garantida pelo princípio federativo e a formulação pela subsidiariedade de que os entes menores devem ter sua autonomia e liberdade preservados. ${ }^{12}$

\footnotetext{
${ }^{10}$ Silvia Torres relaciona diretamente a subsidiariedade e a federação: "A vinculação do princípio federativo ao princípio da subsidiariedade é incontestável enquanto os postulados deste se realizam, de forma mais expressiva, na estrutura de uma organização federal, na qual se encontram distintos grupos superpostos, reconhecidos em sua pluralidade e relativa autosuficiência. De fato, tendo o federalismo a diversidade e o pluralismo de interesses como fundamento, conclui-se, pelo que já se disse até então sobre a subsidiariedade, que não é senão por meio dela que se pode alcançar, de forma mais apropriada, a finalidade do Estado federal, que é, em poucas palavras, justamente a harmonia entre os fatores que lhe servem de alicerce, vale dizer, o equilíbrio entre forças contraditórias da unidade e da diversidade. [...] E se no plano estritamente político o princípio da subsidiariedade tem na organização federal a sua mais significativa expressão, na esfera jurídica a afirmativa não há de ser diversa eis que, como princípio de repartição de competência, a subsidiariedade se aplica de imediato ao federalismo, que é modo de divisão de competências constitucionais por excelência, tendo, nesta partilha de poderes e encargos, o alicerce de todo o seu edifício constitucional." (grifo nosso) TORRES, Silvia Faber. O princípio da subsidiariedade no direito público contemporâneo. Rio de Janeiro: Renovar, 2001. p. 211-213. Sobre este ponto de vista e suas controvérsias, ver também MARTINS, Margarida Salema D'Oliveira. O princípio da subsidiariedade em perspectiva jurídico-política. Coimbra: Coimbra Editora, 2003. p. 84-88.

${ }_{11}^{1}$ JORDAN, Andrew, loc. cit.: "At root, [subsidiarity] is a federal term, used to allocate powers between different levels of government. In fact subsidiarity - and the conscious act of considering a priori the allocation of competences which lies behind it - is in many respects the defining feature of federalism."

${ }^{12}$ VILHENA, Maria do Rosário. O princípio da subsidiariedade no direito comunitário. Coimbra: Almedina, 2002. p. 32-33.
} 
Esta interpretação da subsidiariedade parece coadunar-se com a realidade constitucional brasileira. São exemplos concretos disto os artigos 21 e 22, que estabelecem a competência privativa da União; o art. 23, que estabelece a competência comum da União, Estados, Distrito Federal e Municípios; o art. 24, que atribui competência legislativa concorrente e o art. 30, veiculando as competências municipais. Na fase pré-constitucional de debates parlamentares, certamente se teve em conta a noção de que determinados assuntos deveriam ser tratados por esferas maiores, enquanto outros poderiam ser deixados aos cuidados de esferas menores. Esta é uma primeira função, de índole eminentemente políticoconstitucional, que este princípio é chamado a cumprir no seio de uma federação.

Uma segunda função é a de princípio interpretativo a colmatar o sentido e alcance das competências previamente atribuídas pelo constituinte. Por vezes, não se tem a real percepção de até onde vai o âmbito de competência delimitado na Constituição. Exemplo cristalino desta hipótese é o competência dos Municípios para legislar sobre "assuntos de interesse local" (art. 30, I, CRFB 1988). Não deixa de ser um conceito jurídico aberto e o recurso à subsidiariedade, mediante os critérios que a informam e que serão demonstrados abaixo, pode servir de parâmetro para o preenchimento do sentido desta norma no caso concreto.

Assim, ainda que não se reconheça uma eficácia normativa direta do princípio por ausência de expressa previsão constitucional, impende reconhecê-lo ao menos como princípio metajurídico informador da atividade legiferante no tocante à repartição de atribuições, bem como supedâneo interpretativo para a aferição da extensão das competências atribuídas.

No plano infra-constitucional e mantendo o foco na questão ambiental, a presença da subsidiariedade pode ser extraída do texto de alguns artigos da Lei $\mathrm{n}^{\circ}$. 6.938/91 (Lei da Política Nacional do Meio Ambiente) e da Resolução CONAMA nº. 237/97. Tais artigos tratam de uma denominada atuação supletiva do IBAMA em matérias como fiscalização, poder normativo e licenciamento. Embora considerações mais profundas sobre o tema serão feitas adiante, propugna-se neste trabalho que a expressão supletividade do texto legal é, ainda que de forma imprecisa ${ }^{13}$, a consagração da subsidiariedade em matéria de atuação dos diversos órgãos ambientais dos diferentes entes federativos.

\footnotetext{
${ }^{13}$ A imprecisão no uso dos termos supletividade e subsidiariedade como sinônimos na técnica jurídica é apontada pela doutrina. Margarida Salema d'Oliveira Martins ensina: "Daí que a expressão supletividade seja associada a uma técnica utilizada pelo legislador, constituinte ou ordinário, para resolver problemas de lacunas, insuficiências ou omissões de dados ordenamento normativos. [...] A supletividade surge associada a uma técnica que serve apenas para indicar ao operador jurídico quais as normas a aplicar [...] enquanto a subsidiariedade foi trazida para o domínio do direito para aí servir de princípio delimitador de competências." MARTINS, Margarida Salema
} 


\section{CRITÉRIOS DE APLICAÇÃO DO PRINCÍPIO DA SUBSIDIARIEDADE E SUA RELAÇÃO COM O DIREITO AMBIENTAL}

A forma ótima de aplicação do princípio é ainda uma vexata quaestio, variando consideravelmente de um autor para outro a nomenclatura e formulação dos critérios para a aplicação do princípio da subsidiariedade. Contudo, a partir da leitura do art. $5^{\circ}$ do Tratado da União Européia (acima apresentado), podem ser extraídos dois critérios principais ${ }^{14}$ para a compreensão de sua aplicação: a exclusividade e a eficácia ${ }^{15}$.

A) Exclusividade: o critério da exclusividade funciona como pressuposto lógico da aplicação do princípio da subsidiariedade. Somente haverá espaço para a atuação da subsidiariedade caso não haja normas criando uma competência exclusiva em favor de um determinado ente. Trata-se de uma exclusão prévia da possibilidade de ação dos demais entes e da aplicação da subsidiariedade pela criação de uma competência exclusiva de um ente determinado.

No ordenamento constitucional brasileiro, a aplicação do método da exclusividade dáse, por exemplo, quanto às competências privativas da União previstas nos arts. 21 e 22 da

D’Oliveira. op. cit. p. 14-15. Não obstante isto, a própria autora, na p. 13 de seu livro já citado, admite que as expressões são usadas indistintamente no direito positivo português. Parece também o legislador brasileiro ter usado sem precisão técnica a expressão supletividade na Lei nº. 6.938/81 e na Resolução CONAMA no. $237 / 97$. Uma análise mais profunda dos dispositivos revela que o conteúdo da norma refere-se muito mais à noção de subsidiariedade, conforme será apresentado mais abaixo.

${ }^{14}$ Fausto de Quadros, em linhas gerais com idéias semelhantes àquelas aqui defendidas, fala de um binômio: "a necessidade da prossecução daquela actividade [pelo ente maior] e a maior eficácia da comunidade maior nessa prossecução". QUADROS, Fausto de. O princípio da subsidiariedade no direito comunitário após o Tratado da União Europeia. Coimbra: Almedina, 1995. p. 18.

${ }^{15}$ Silvia Torres faz um reparo ao critério da eficácia na aplicação do princípio da subsidiariedade: “[...] o princípio da subsidiariedade não se cifra em razões de ordem técnica ou econômica. Ao contrário, como se depreende das próprias palavras da Encíclica Quadragesimo Anno, reproduzidas pela Encíclica Mater et Magistra, o princípio da subsidiariedade é um princípio jurídico, enquanto fundando na justiça. [...] Assim, embora o texto pontifício faça alusão à eficácia, em nenhum momento, porém, considera a subsidiariedade como um princípio técnico, que almeja uma maior eficiência ou um maior rendimento no âmbito econômico, senão que a tem como um princípio estrito de justiça. [...] O princípio da subsidiariedade, portanto, como asseveram Calvez e Perrin, não é uma 'fórmula pragmática' que diga com uma maior ou menor eficácia dos atores sociais, mas indica uma função natural do Estado na garantia do bem comum e da justiça distributiva." TORRES, Silvia Faber. op. cit. p. 21-22. Concordamos com a afirmação de que a subsidiariedade é também um princípio jurídico que tem por base a consagração da justiça e do bem comum na atuação estatal. Não vemos, todavia, como esta perspectiva exclui a existência de uma faceta técnica (e, por vezes, econômica) de distribuição satisfatoriamente eficaz de atribuições entre entes diferentes presentes na sociedade. 
Constituição. Nestes setores, não poderá haver, em regra, atuação de Estados e Municípios. Mais há um outro aspecto do critério de exclusividade que, embora pareça óbvio, cabe salientar: a exclusividade territorial. Não se pode aceitar, em regra, que sobre a área de um ente maior venha um ente menor a atuar, sendo que este tão-somente agirá na área compreendida em seus limites territoriais. O critério territorial de exercício de atribuições também funciona como um critério que, a priori, exclui a atividade dos entes menores.

B) Eficácia: o critério da eficácia estabelece que a comunidade maior tão-somente deverá interferir em assuntos cuja gestão satisfatória não possa ser feita de modo eficaz pela comunidade menor.

A questão que se coloca é a da importância do grau de eficácia demonstrado pelo ente menor. Neste ponto, há divergência doutrinária. Distinguem-se duas posições principais quanto ao critério da eficácia.

Uma primeira posição entende a subsidiariedade como um princípio de exclusão: o ente maior somente atuaria se o ente menor demonstrasse uma inaptidão total para a consecução de um determinado fim. Nesta perspectiva, a atuação do ente maior é feita com exclusão da atuação do ente menor. ${ }^{16}$ A segunda postura encara a subsidiariedade primariamente como um princípio de assistência mediante cooperação: se o ente menor revelar uma dificuldade, ainda que parcial, na gestão de uma determinada situação, o ente maior deve, em cooperação com o ente menor, fornecer os subsídios para que o ente menor possa gerir o tema que lhe é afeto. Destarte, mesmo naquelas circunstâncias em que o ente menor não é plenamente capaz de implementar uma gestão satisfatória sozinho, não se configura a exclusão deste, mas sim uma colaboração do ente maior para que o ente inferior possa, também ele participando, buscar a gestão satisfatória de uma dada matéria. Cria-se aqui uma competência partilhada ou, caso não seja necessária a assunção direta de uma partilha

\footnotetext{
${ }^{16}$ Esta a postura de Fausto de Quadros, no âmbito da União Européia: "De facto, a expressão atribuições 'partilhadas' quer significar, segundo os dicionários, atribuições divididas, atribuições distribuídas simultaneamente pela Comunidade e pelos Estados membros, o que imporia, ou pelo menos permitira, que elas fossem exercidas em simultâneo, e conjuntamente, por aquela e por estes. Ora, não é isso, de modo algum, o que acontece na subsidiariedade: o que esta postula é que, como já se explicou e ainda melhor se explicará adiante, as atribuições sejam exercidas ou pelos Estados ou pela Comunidade, mas só poderão ser prosseguidas por este se os Estados não forem capazes de as exercer em determinadas condições. Portanto, não há partilha, mas, sim, concorrência, porque as atribuições em causa não podem ser exercidas simultanea e conjuntamente pelos Estados e pela Comunidade.” QUADROS, Fausto de. op. cit. p. 38-39.
} 
com o ente menor, ao menos uma competência de apoio ou coordenação do ente superior em relação à atuação dos entes inferiores. A tônica aqui é a da atuação conjunta ou simultânea e parece coadunar-se com a própria etimologia da palavra subsidium, que significa, em língua latina, assistência, auxílio, ajuda. ${ }^{17}$ Apenas em um segundo momento, mediante a constatação da absoluta inépcia do ente menor em gerir aquela matéria, nasceria para o ente maior a possibilidade de assumir plenamente a gestão da matéria que caberia ao ente menor.

Em verdade, a discussão acima demonstra como a subsidiariedade está intimamente ligada ao princípio da proporcionalidade: a subsidiariedade como princípio atribuidor e limitador de competência deverá ser balizada pelo critério da necessidade da atuação do ente maior na consecução da atuação mais eficaz e satisfatória possível. Além disso, a atuação do ente superior não deve exceder a medida do necessário para a consecução dos fins que o ente inferior não é capaz de realizar sozinho. ${ }^{18}$

Na seara ambiental, uma tomada de posição faz-se necessária. A opção que parece mais consentânea com a índole do sistema constitucional brasileiro em matéria ambiental é a da interpretação da subsidiariedade como princípio de auxílio cooperativo, vez que o art. 225 da Constituição da República estabelece a obrigatoriedade de o Poder Público e de a coletividade defenderem e preservarem o meio ambiente para as presentes e futuras gerações. ${ }^{19}$ A expressão "Poder Público", utilizada de modo genérico, deve ser interpretada como a englobar União, Estados e Municípios ${ }^{20}$. Não por acaso, o art. 23, VI da Constituição

\footnotetext{
${ }^{17}$ SARAIVA, F. R. DOS SANTOS. Novíssimo dicionário latino-português. 9. ed. Rio de Janeiro: Garnier, 1927.

${ }^{18}$ No Tratado da União Européia, o princípio da proporcionalidade também foi expressamente consignado em estreita relação com a subsidiariedade. Maria do Rosário Vilhena explicita que "Subsidiariedade e proporcionalidade, muito embora sejam questões distintas e autônomas, estão intimamente associadas, e são suscitadas usualmente no âmbito de um mesmo debate, a saber, o relativo ao exercício das competências comunitárias. [...] O princípio da proporcionalidade, enquanto princípio geral de direito comunitário, intervém em todos os domínios e competência comunitária, inclusivamente naqueles onde essa competência é exclusiva. Toda e qualquer acção comunitária está submetida ao seu crivo, competindo ao princípio da proporcionalidade definir e regulamentar a intensidade e a natureza da medida a adoptar, determinando assim qual a acção a encetar no caso concreto, a qual não deverá exceder o que é necessário e útil à realização dos objectivos visados. Deste modo, o campo de aplicação do princípio é muito mais vasto do que o do princípio da subsidiariedade, o qual, como já tivemos oportunidade de demonstrar, tem a sua aplicação restrita ao domínio das competências comunitárias concorrentes. Assim, subsidiariedade e proporcionalidade só actuarão em conjunto quando estejam em causa competências concorrentes." VILHENA, Maria do Rosário. op. cit. p. 148-149.

${ }^{19}$ Art. 225. Todos têm direito ao meio ambiente ecologicamente equilibrado, bem de uso comum do povo e essencial à sadia qualidade de vida, impondo-se ao Poder Público e à coletividade o dever de defendê-lo e preservá-lo para as presentes e futuras gerações.

20 “[...] entendo ser inequívoco que tanto a União, os Estados e os Municípios são dotados de amplas competências ambientais." ANTUNES, Paulo de Bessa. Direito ambiental. 7. ed. Rio de Janeiro: Lumen Juris, 2004. p. 90.22
} 
estabelece ser competência comum de todos os entes federados aquela de, em verdadeira cooperação administrativa, proteger o meio ambiente e combater a poluição em qualquer de suas formas $^{22}$. Indo além, estabelece a Lei Maior que também a coletividade tem o dever de proteger o meio-ambiente. Desta forma, a idéia consagrada pelo constituinte é a de que há um dever de todos os entes federados ${ }^{21}$ e mesmo da coletividade de preservarem o ambiente.

Pelo princípio da subsidiariedade, se um ente menor logra realizar uma efetiva proteção ambiental sem o concurso de outros entes, não se faz necessário o auxílio de entes maiores, sob pena de repetição indevida de atuação e alocação perdulária de recursos. Contudo, se houver alguma insuficiência na proteção ambiental por parte de entes menores (o que, desafortunadamente, é relativamente comum na experiência brasileira), deve o ente maior, por imperativo constitucional, coadjuvar o ente menor nas atividades de proteção. $\mathrm{O}$ ambiente equilibrado e saudável diz respeito ao bem de todos, não cabendo aqui o Poder Público de esferas superiores "lavar as mãos" sobre o tema. Isto é assim pela peculiaridade do bem jurídico em jogo, qual seja, o meio ambiente. ${ }^{22}$ De fato, o meio ambiente não respeita limites territoriais estabelecidos pelo engenho humano; os ecossistemas estendem-se por municípios e estados diversos; desastres ambientais podem causar transtornos a toda uma nação ou continente. Impõe-se a atuação conjunta de preservação e mesmo a interferência do ente maior sempre que o ente menor demonstrar não conseguir, com eficácia, gerir e preservar satisfatoriamente o ambiente.

Os entes menores, se realizam com eficácia satisfatória a gestão do meio ambiente localizado em seu território, não devem sofrer ingerência externa de entes maiores. Contudo, se esta gestão não for satisfatória, está autorizado o ente maior a agir, seja assumindo total ou parcialmente a gestão da atividade (neste último caso de parcialidade, deverá haver uma partilha de gestão). Se a situação afetar territórios de dois ou mais entes menores, duas soluções são cabíveis: poderá haver uma co-gestão mediante convênio entre os entes menores envolvidos, buscando a atuação eficaz e satisfatória no tema; poderia também o ente maior

\footnotetext{
“A competência comum, portanto, é uma imposição constitucional para que os diversos integrantes da Federação atuem em cooperação administrativa recíproca, visando a resguardar os bens ambientais.” Idem, p. 88. ${ }^{21}$ Aqui não se deseja adentrar a acendrada polêmica a respeito de ser o Município ente federativo. Esta querela é de todo irrelevante para os fins deste artigo: importante é verificar que o Município é uma realidade institucional menor que Estados e União, independentemente de ser classificado ou não como ente federativo.

${ }^{22}$ Sobre as especificidades da natureza jurídica do meio ambiente, ver MOTA, Mauricio Jorge P.; PEREIRA, Daniel Queiroz; PEREIRA, Vítor Pimentel. Direito ambiental das cidades: novas perspectivas acerca da sustentabilidade das regiões urbanas. Revista de Direito da Cidade, Rio de Janeiro, ano 1, n. ${ }^{\text {3 }}$, nov. 2007. p. 6470 .
}

Revista Quaestio luris, vol.04, no01. ISSN 1516-0351 p.747-770 759 
atuar, pelo fato de a questão ultrapassar o âmbito territorial de atuação de cada ente menor individualmente considerado. Caso o convênio de gestão compartilhada entre os entes menores afetados não seja efetivamente realizado ou mesmo se a gestão implantada não realizar satisfatoriamente os fins propostos, também aí se imporia a ação do ente maior.

Em todo caso, deve-se ter em conta, na atuação do ente maior, a magnitude do interesse levado em consideração. Ainda que, por exemplo, um desastre ecológico de proporções consideráveis haja ocorrido no território de um Estado, a possibilidade de afetar um território mais amplo que o estadual autorizaria a União a atuar, juntamente com o Estado, na questão ambiental. A doutrina indica, para a explicação deste fenômeno, o critério da predominância do interesse (nacional, regional ou local) na partição de competências, ${ }^{23}$ mas a presença de um impacto ou ecossistema cuja importância desborde os limites do território do ente menor pode ser explicada também pelo recurso à subsidiariedade. De fato, quando a possibilidade de dano, a importância de uma área ou a carga simbólica de um monumento natural revestem-se de caráter relevante, ocorre uma espécie de presunção prévia de que a proteção eficaz daquela situação só poderá ser realizada por meios que somente o ente maior poderá oferecer. Presume-se aqui a ineficácia do ente menor para gerir sozinho aquela área determinada.

Nos casos acima, é comum que o legislador lance mão desta presunção, aplicando uma forma qualificada do critério da exclusividade acima exposto. Devido à importância de um dado ecossistema, o legislador estabelece, por uma norma, a retirada da gestão ambiental de uma área plenamente compreendida no território de um ente menor, deferindo-a a um ente maior. É o que ocorre com certas áreas especiais (como os Parques Nacionais) encravadas totalmente no território de entes menores mas que tem sua administração cometida a entes maiores. Este critério de exclusividade - que atua como pressuposto lógico da repartição de competências - permite ao legislador empreender as valorações necessárias sobre a importância de determinadas áreas e o grau de proteção que pretende conferir a elas.

Sem esta possibilidade de aplicação do critério da exclusividade, a subsidiariedade transformar-se-ia num engessamento da atuação do Poder Público, pois jamais o ente maior

\footnotetext{
${ }^{23}$ Estabelecendo como critério a predominância do interesse (interesse geral, regional ou local) como critério para legitimação da atuação dos entes federados, cf. SILVA, Vicente Gomes da. Legislação ambiental comentada. 3. ed. Belo Horizonte: Fórum, 2006. p. 83-84; FARIAS, Talden. A repartição de competências para o licenciamento ambiental e a atuação dos municípios. Revista de Direito Ambiental, São Paulo, v. 11, no ${ }^{\circ} 43$, jul./set. 2006. p. 255-256. Numa linha de pensamento também similar, mas na União Européia, cf. ZILIOLI, Chiara. L'applicazione del principio di sussidiarietà nel diritto comunitario dell'ambiente. Rivista Giuridica dell'Ambiente. Milano, fasc. 3-4, 1995. p. 542-545.
} 
poderia interferir num território que pertencesse ao menor. Não é essa a melhor forma de compreender o princípio. Mesmo que a área haja sido reservada à gestão de um ente maior, é comum que, na prática, ocorra uma colaboração do ente menor em cujo território aquele ecossistema está localizado. Tomemos, por exemplo, a gestão do Parque Nacional da Tijuca, área de floresta urbana encravada no Município do Rio de Janeiro. Embora o parque esteja totalmente inserido em território municipal, a gestão da área, devido à sua relevância e por expressa previsão em decreto, é feita pelo governo federal (IBAMA). Não obstante isto, o município disponibiliza membros da Guarda Municipal para a vigilância das áreas mais movimentadas da floresta.

Outra prática de cooperação, desta feita consagrada em lei, é o art. 26 da Lei ${ }^{\circ}$. 9.985/2000, o qual estabelece a figura do "mosaico", isto é, um conjunto de unidades de conservação de categorias diferentes ou não, próximas, justapostas ou sobrepostas, e outras áreas protegidas públicas ou privadas. Caso uma área seja reconhecida como mosaico pelo Ministério do Meio Ambiente, a gestão desta, por mandamento legal, deverá ser feita de forma integrada e participativa entre os três entes federados e a sociedade civil, considerandose os seus distintos objetivos de conservação, de forma a compatibilizar a presença da biodiversidade, a valorização da sociodiversidade e o desenvolvimento sustentável no contexto regional. Cria-se um conselho de gestão em que deverão estar representados os três níveis federativos, devendo esta representação contemplar, quando couber, os órgãos ambientais de cada ente, num exemplo claro de que a atuação da subsidiariedade em matéria ambiental deve ser, em primeiro lugar - e sempre que possível -, inclusiva de todas as esferas envolvidas.

\section{A QUESTÃO DO LICENCIAMENTO AMBIENTAL À LUZ DA SUBSIDIARIEDADE}

A questão da partição de competências no licenciamento ambiental é das mais tormentosas no direito ambiental brasileiro. Neste sentido, a subsidiariedade e seus critérios de aplicação podem servir de parâmetro para a delimitação do órgão competente para a concessão da licença. É inclusive possível a interpretação da Lei no . 6.938/81 e da Resolução 
CONAMA $n^{\circ}$. 237/97 como consagradoras da subsidiariedade ambiental no ordenamento positivo nacional.

Conforme enunciado acima, a Lei $\mathrm{n}^{\circ}$. 6.938/81 traz o conceito de atuação supletiva do IBAMA quanto ao licenciamento ambiental:

\begin{abstract}
Art. 10 - A construção, instalação, ampliação e funcionamento de estabelecimentos e atividades utilizadoras de recursos ambientais, considerados efetiva e potencialmente poluidores, bem como os capazes, sob qualquer forma, de causar degradação ambiental, dependerão de prévio licenciamento de órgão estadual competente, integrante do Sistema Nacional do Meio Ambiente - SISNAMA, e do Instituto Brasileiro do Meio Ambiente e Recursos Naturais Renováveis - IBAMA, em caráter supletivo, sem prejuízo de outras licenças exigíveis.

$\S 3^{\circ} \mathrm{O}$ órgão estadual do meio ambiente e IBAMA, esta em caráter supletivo, poderão, se necessário e sem prejuízo das penalidades pecuniárias cabíveis, determinar a redução das atividades geradoras de poluição, para manter as emissões gasosas, os efluentes líquidos e os resíduos sólidos dentro das condições e limites estipulados no licenciamento concedido."
\end{abstract}

Art. 11. Compete ao IBAMA propor ao CONAMA normas e padrões para implantação, acompanhamento e fiscalização do licenciamento previsto no artigo anterior, além das que forem oriundas do próprio CONAMA.

$\S 1^{\circ}$ A fiscalização e o controle da aplicação de critérios, normas e padrões de qualidade ambiental serão exercidos pelo IBAMA, em caráter supletivo da atuação do órgão estadual e municipal competentes. (grifo nosso)

Duas formas de interpretação desta supletividade surgem. A primeira instaura verdadeira tutela do IBAMA $^{24}$ sobre a atividade dos órgãos ambientais estaduais, sendo o termo supletividade entendido como sinônimo de "supervisão" ou, em alguns casos, como de concorrência entre o IBAMA e o órgão estadual, independentemente de comprovada demonstração de ineficiência do Estado federado. Neste entendimento, o requerente da licença ambiental poderia dirigir-se tanto ao IBAMA quanto ao órgão ambiental estadual para obter a licença, ou, como querem alguns, estaria obrigado a buscar o licenciamento junto ao IBAMA e aos órgãos estaduais. A segunda interpretação aproxima a supletividade do conceito de subsidiariedade: a atuação do IBAMA sobre questões usualmente afetas ao Estado federado somente estaria autorizada quando expressamente prevista em lei a atuação exclusiva da autarquia federal (critério da exclusividade) ou se o órgão ambiental estadual demonstrasse verdadeira inépcia na gestão ambiental (critério da eficácia).

A segunda postura parece ser a mais consentânea com o modo pelo qual se estrutura a federação brasileira. Aqui, entra em cena, no direito ambiental, a função precípua da

\footnotetext{
${ }^{24}$ Para explanação da supletividade como tutela, cf. MARTINS, Margarida Salema D’Oliveira. op. cit. p. 461.
} 
subsidiariedade: delimitar competências, conferindo-se preferência à atuação do ente menor, desde que possa realizar uma atividade determinada de modo eficaz. Assim, descendo à hipótese concreta, pela aplicação da subsidiariedade, não pode o IBAMA, em regra, ingerir-se no licenciamento ambiental cometido aos órgãos ambientais estaduais em áreas pertencentes aos Estados. Deixando de lado as hipóteses de reserva de atuação expressa em lei (critério da exclusividade) e de situações que, embora ocorridas no território estadual, por sua dimensão ou efeitos apresentam vulto e interesse gerais, ${ }^{25}$ a atuação do IBAMA no território estadual deve se dar tão-somente quando o órgão estadual demonstrar não se desincumbir de sua função com eficácia satisfatória: ou seja, quando for inepto (por falta de conhecimento técnico, por exemplo) ou por uma reiterada omissão em agir. ${ }^{26}$ Evita-se com isso a criação de um ambiente de desconfiança em relação à qualidade do trabalho desempenhado pelo órgão estadual.

Também a jurisprudência do Superior Tribunal de Justiça já se pronunciou sobre o tema. Ainda que os votos dos Ministros não aludam expressamente ao termo subsidiariedade, as soluções jurídicas propostas em dois casos a serem apresentados revelam, implicitamente, um raciocínio muito similar àquele propugnado pelo princípio da subsidiariedade.

No REsp $763.377^{2728}$, a $1^{\mathrm{a}}$. Turma do STJ tratou de caso em que se pretendia a construção de um complexo hoteleiro no município fluminense de Angra dos Reis. A licença ambiental foi concedida pelo órgão estadual, mas foi proposta uma ação civil pública com pedido liminar de imediata paralisação das obras. A liminar foi concedida e confirmada pelo Tribunal Regional Federal da $2^{\text {a }}$. Região, sob o argumento de que, em face do vulto do empreendimento, era "Indispensável que os órgãos técnicos especializados das três esferas federativas manifestem-se nos autos, para que possa ser afastada qualquer dúvida acerca das questões suscitadas."

\footnotetext{
${ }^{25}$ Esta aplicação do critério da exclusividade, reservando o licenciamento ao IBAMA em certas situações, por meio do mecanismo da predominância do interesse ou da prévia presunção de magnitude, encontra previsão no art. 10, $\S 4^{\circ}$ da Lei $n^{\circ}$. 6.938/81: "Compete ao Instituto Brasileiro do Meio Ambiente e Recursos Naturais Renováveis - IBAMA o licenciamento previsto no caput deste artigo, no caso de atividades e obras com significativo impacto ambiental, de âmbito nacional ou regional." A lei presume que, seja pela relevância do impacto, seja pela extensão do território atingido, estas hipóteses de licenciamento devam ser cometidas diretamente ao ente maior (IBAMA). Maiores concretizações do $\S 4^{\circ}$ do art. 10 serão comentadas mais adiante, na abordagem do art. $4^{\circ}$ da Resolução CONAMA nº. 237/97.

26 “O art. 10, caput, da Lei 6.938/81 prevê que o IBAMA licenciará em caráter supletivo, em relação ao órgão estadual ambiental. A atuação supletiva do IBAMA, apesar de a lei não indicar os seus parâmetros, deverá ocorrer, principalmente, em duas situações: se o órgão estadual ambiental for inepto ou se o órgão permanecer inerte ou omisso." MACHADO, Paulo Affonso Leme. Direito Ambiental Brasileiro. 12. ed. São Paulo: Malheiros, 2004. p. 261.

${ }^{27}$ BRASIL. Superior Tribunal de Justiça. REsp 763.377-RJ. 1ª Turma. Relator Ministro Francisco Falcão. DJ

${ }^{28} .08 .2007$. p. 192.
} 
O STJ deu provimento ao recurso especial do empreendedor para permitir a construção, vez que demonstrado que a construtora havia realizado diligente e corretamente todos os procedimentos necessários à obtenção da licença perante o órgão estadual. Reconhecendo a competência do órgão estadual para a concessão da licença, o STJ decidiu que não caberia a participação do IBAMA neste ato. Segundo o voto do Ministro Relator, a situação somente mudaria de figura se restasse demonstrado nos autos que, no caso concreto, o órgão estadual não estiva apto a averiguar eficazmente o potencial danoso do empreendimento, o que não foi comprovado. Assim, ainda que de modo implícito, o STJ, por seu acórdão, prestigiou a subsidiariedade ao dar pleno cumprimento ao art. 10 da Lei ${ }^{\circ}$. $6.983 / 81$.

No REsp 818.666-PR ${ }^{30}$, também da relatoria do Ministro Francisco Falcão, a decisão foi diametralmente oposta àquela acima exposta. Neste caso, o IBAMA atuara na concessão de licença ambiental para instalação de empreendimento ligado à indústria do aço. Foi questionada a concessão de licença ambiental pelo IBAMA em detrimento do órgão ambiental estadual. O voto do relator, baseado na decisão do Tribunal Regional Federal da $4^{\text {a }}$. Região, foi lapidar: asseverou a competência do IBAMA na espécie pois restara demonstrado que o órgão estadual fora inepto na apreciação do pedido de licenciamento ambiental. À época, não havia estrutura e quadro funcional suficiente nos Estados para realizar o licenciamento ambiental. Daí a possibilidade (e mesmo o imperativo) de atuação do IBAMA, de modo subsidiário à atuação do órgão estadual. Da interpretação contrario sensu depreendese que, caso houvesse ação satisfatória do órgão estadual, não estaria legitimada a ação do IBAMA.

Na hipótese da inépcia, surge a possibilidade de o IBAMA, substituindo-se ao órgão ambiental estadual, atuar na concessão da licença. Desta maneira, conforme já exposto, também aqui o princípio da subsidiariedade revela sua dúplice função. A primeira, como princípio informador de alterações legislativas em matéria ambiental que visem a delimitar competências, devendo o legislador buscar prestigiar a autonomia dos entes menores e a descentralização como mecanismo de eficácia de gestão. A segunda função é de natureza interpretativa das atuais disposições sobre competência para concessão de licenças ambientais, a fim de que, na hermenêutica de dispositivos legais de interpretação não pacificada, privilegie-se a interpretação que confira maior efetividade ao princípio da subsidiariedade e à autonomia dos entes menores. ${ }^{31}$ 
Em matéria ambiental, é digna de nota a Resolução CONAMA nº. 237/97. Esta Resolução, ao estabelecer a repartição de competências em matéria de licenciamento ambiental, fez uso, ainda que implicitamente, de mecanismos consagrados pelo princípio da subsidiariedade. Sua maior fragilidade reside na subversão do esquema tradicional da hierarquia normativa: cria novas hipóteses de atribuição de competência sem a devida previsão legal. ${ }^{29}$ A melhor solução seria a da inserção destas matérias no texto da Lei $\mathrm{n}^{\circ}$. $6.938 / 81$.

$\mathrm{O}$ art. $4^{\circ}$ configura uma aplicação do critério da exclusividade. A Resolução presume que determinadas atividades, por sua extensão ou importância, devem ter licenciamento realizado pelo IBAMA. São competência de licenciamento desta autarquia federal as atividades: I) localizadas ou desenvolvidas conjuntamente no Brasil e em país limítrofe, no mar territorial, na plataforma continental, na zona econômica exclusiva, em terras indígenas ou em unidades de conservação do domínio da União; II) localizadas ou desenvolvidas em dois ou mais Estados; III) cujos impactos ambientais diretos ultrapassem os limites territoriais do País ou de um ou mais Estados; IV) destinadas a pesquisar, lavrar, produzir, beneficiar, transportar, armazenar e dispor material radioativo, em qualquer estágio, ou que utilizem energia nuclear em qualquer de suas formas e aplicações; V) bases ou empreendimentos militares, quando couber.

Deve ser ressaltado o art. $6^{\circ}$, que estabelece a existência de licenciamento em âmbito municipal. ${ }^{33}$ Tal criação infra-legal coaduna-se com tudo aquilo que vem sendo proposto ao longo desta exposição, dando efetividade ao próprio art. 30, I, CRFB 1988, com a possibilidade de os Municípios, enquanto entes autônomos, concederem licenças ambientais

\footnotetext{
${ }^{29}$ Paulo Affonso Leme Machado não hesita em vergastar a Resolução quanto ao tema da atribuição de competências por ato infra-legal, inquinando-a de inconstitucionalidade. MACHADO, Paulo Affonso Leme. op. cit. p.100-101. Identificando um conjunto de ilegalidades e inconstitucionalidades na Resolução, cf. ANDRADE, Filippe Augusto Vieira de. Resolução CONAMA n. 237, de 19.12.1998: um ato normativo inválido pela eiva da inconstitucionalidade e da ilegalidade. Revista de Direito Ambiental, São Paulo, v. 4, nº. 13, jan./mar. 1999; VAN ACKER, Francisco Thomaz. Breves considerações sobre a Resolução 237, de 19.12.1997, do CONAMA, que estabelece critérios para o licenciamento ambiental. Revista de Direito Ambiental, São Paulo, v. 2, nº .8 , out./dez. 1997, p. 167-168. 33 Art. $6^{\circ}$ - Compete ao órgão ambiental municipal, ouvidos os órgãos competentes da União, dos Estados e do Distrito Federal, quando couber, o licenciamento ambiental de empreendimentos e atividades de impacto ambiental local e daquelas que lhe forem delegadas pelo Estado por instrumento legal ou convênio.
} 
com relação a áreas localizadas em seu território e cujo impacto ambiental seja eminentemente local. $^{30}$

Ademais, o art. $7^{\circ}$ da referida Resolução assemelha-se a um verdadeiro libelo à subsidiariedade ao estatuir que "Os empreendimentos e atividades serão licenciados em um único nível de competência, conforme estabelecido nos artigos anteriores." A descentralização das atividades e a exigência de um único licenciamento contribuem para a racionalização do procedimento administrativo de licenciamento e para simplificar a vida do requerente, evitando inúteis gastos de tempo e capital tanto da Administração Pública quanto dos particulares. $^{31}$

Também o art. 16 consagra que o não cumprimento dos prazos estipulados por parte do órgão ambiental ensejará o licenciamento por atuação do órgão que detenha competência para atuar supletivamente. Trata-se de uma salutar previsão que presume a inépcia do órgão remisso quando houver dilação excessiva de prazo, liberando assim o particular das malhas de uma burocracia infindável.

\section{CONCLUSÃO}

O princípio da subsidiariedade nasce no pensamento católico como um princípio de justa e devida repartição de atribuições ou competências dentro das esferas sobrepostas que compõem o tecido social, buscando garantir a devida autonomia e liberdade dos vários entes que a compõem. Daí migrou para um princípio político e jurídico de repartição de

\footnotetext{
${ }^{30}$ Talden Farias argumenta que o art. $6^{\circ}$ não é inconstitucional, vez que a possibilidade de os Municípios concederem licença ambiental inclui-se entre as prerrogativas do federalismo brasileiro, de modo que o referido artigo simplesmente reconheceu uma competência constitucionalmente determinada que garante a autonomia municipal. FARIAS, Talden. op. cit. p. 262.

${ }^{31}$ Realista o diagnóstico de Talden Farias sobre os efeitos nefastos da superposição de competências em matéria de licenciamento: "O objetivo de repartição de competências em matéria ambiental é evitar a duplicidade de esforços, pois se cada ente federativo desempenhar a sua competência originária o licenciamento ambiental será um instrumento mais eficaz. [...] Por vezes dois ou mais entes federativos manifestam interesse em licenciar um determinado tipo de atividade econômica, que apresenta certos dividendos políticos, ao mesmo tempo em que em relação a outros tipos de atividade não tão interessantes do ponto de vista político ou econômico a luta é para não fazer o licenciamento. Essa indefinição coloca em jogo a imagem do Sistema Nacional do Meio Ambiente e os próprios órgãos administrativos de meio ambiente envolvidos, além de trazer prejuízos aos responsáveis pelas atividades a serem licenciadas, na medida em que um órgão ambiental pode embargar um empreendimento licenciado por outro órgão ambiental afirmando que a licença concedida pelo outro não tem valor.” Idem, p. 250251.
}

Revista Quaestio luris, vol.04, no01. ISSN 1516-0351 p.747-770 766 
competências entre Estados e no interior destes, alcançando positivação expressa no Tratado da União Européia.

A federação é tida como locus privilegiado de atuação da subsidiariedade, por sua própria estrutura descentralizada e de repartição de competências entre entes federativos maiores e menores. Neste sentido, a subsidiariedade também tem um papel a cumprir no Brasil, uma república federativa.

A aplicação do princípio da subsidiariedade deve obedecer a dois critérios: o de exclusividade e o de eficácia satisfatória. Pelo primeiro, caso haja uma norma que crie uma competência exclusiva em favor de um determinado ente, exclui-se a atuação de outros entes. Pelo segundo, somente deve haver interferência do poder superior sobre o ente inferior caso este não logre realizar satisfatoriamente a gestão das atividades que lhe são afetas. Caso isto ocorra, havendo absoluta inépcia do ente menor, o ente superior deverá assumir completamente a atividade. Se a inépcia for meramente parcial, é preferível a instituição de um mecanismo de gestão partilhada.

Em matéria de meio ambiente, sempre que um ente menor não for capaz de geri-lo sozinho de maneira satisfatória, urge a conservação do patrimônio ambiental sadio por meio de uma ação concertada de todos os entes federativos, numa aplicação da subsidiariedade em seu aspecto positivo.

Quanto ao licenciamento ambiental, este deve ser realizado tendo em vista a aplicação do princípio da subsidiariedade. O termo supletividade presente na Lei $\mathrm{n}^{\mathrm{o}}$. 6.938/81 e na Resolução CONAMA nº. 237/97 deve ser interpretado como sendo uma aplicação concreta do princípio da subsidiariedade em matéria ambiental. Há posições relevantes na doutrina e jurisprudência que, embora implicitamente, reconhecem interpretação semelhante à supletividade prevista em lei.

Em resumo, o princípio da subsidiariedade na temática ambiental estabelece que os entes menores devam buscar a preservação de modo satisfatório do meio ambiente no âmbito de seus territórios. Contudo, especialmente na matéria em exame e em razão da especial natureza de que está revestido o bem jurídico meio ambiente, não pode a subsidiariedade ser compreendida como mecanismo de exclusão absoluta da atuação de outras esferas: sua reta interpretação é a de que, sempre que necessário à manutenção satisfatória do ambiente sadio, deve haver atuação conjunta das diversas esferas de poder da federação. Obviamente, cada esfera atuará somente naquilo em que tiver capacidade real e efetiva de ação. As atuações 
serão, pois, conjuntas na medida das capacidades (técnicas, econômicas, financeiras) de cada ente. Assim compreendida, a subsidiariedade pode se tornar um relevante instrumento teórico a serviço da salvaguarda da autonomia federativa e da liberdade dos entes menores que compõem uma sociedade.

\section{REFERÊNCIAS}

ANDRADE, Filippe Augusto Vieira de. Resolução CONAMA n. 237, de 19.12.1998: um ato normativo inválido pela eiva da inconstitucionalidade e da ilegalidade. Revista de Direito Ambiental, São Paulo, v. 4, nº. 13, jan./mar. 1999.

ANTUNES, Paulo de Bessa. Direito ambiental. 7. ed. Rio de Janeiro: Lumen Juris, 2004.

BRASIL. Superior Tribunal de Justiça. REsp 763.377-RJ. 1 ${ }^{\mathrm{a}}$. Turma. Relator Ministro Francisco Falcão. DJ 27.08.2007.

Superior Tribunal de Justiça. REsp 818.666-PR. 1 ${ }^{\text {a }}$. Turma. Relator Ministro Francisco Falcão. DJ 25.05.2006.

D’AZEGLIO, Luigi Taparelli. Curso de Direito Natural. Tradução de Pe. Nicolau Rossetti. São Paulo: Anchieta, 1945.

. Saggio teoretico di dritto naturale. Livorno: Vincenzo Mansi, 1845.

FARIAS, Talden. A repartição de competências para o licenciamento ambiental e a atuação dos municípios. Revista de Direito Ambiental, São Paulo, v. 11, nº. 43, jul./set. 2006.

JOÃO XXIII. Carta Encíclica Mater et Magistra, de 15 de maio de 1961. In: SECRETARIA GERAL DA PRESIDÊNCIA DA CÂMARA DOS DEPUTADOS (Org.). Documentos pontifícios sobre questões sociais. Brasília: Imprensa Nacional, 1967.

Carta Encíclica Pacem in Terris, de 11 de abril de 1963. In: SECRETARIA GERAL

DA PRESIDÊNCIA DA CÂMARA DOS DEPUTADOS (Org.). Documentos pontifícios sobre questões sociais. Brasília: Imprensa Nacional, 1967.

JOÃO PAULO II. Carta Encíclica Centesimus Annus, de 1 de maio de 1991. Disponível em: <http://www.vatican.va/holy_father/john_paul_ii/encyclicals/index_po.htm>. Acesso em: 9 set. 2008.

JORDAN, Andrew. Subsidiarity and environmental policy: which level of government should do what in the European Union? CSERGE Working Paper, 1999. Disponível em: 
<http://www.uea.ac.uk/env/cserge/pub/wp/gec/gec_1999_13.htm>. Acesso em: 9 set. 2008.

KRELL, Andreas Joachin. Ordem jurídica e meio ambiente na Alemanha e no Brasil. Alguns aspectos comparativos. Revista de Direito Ambiental, São Paulo, v. 8, nº. 31, jul./set. 2003.

LANGLOIS, José Miguel Ibañes. Doutrina social da Igreja. Lisboa: Rei dos Livros, 1990.

LEÃO XIII. Carta Encíclica Rerum Novarum, de 15 de maio de 1891. In: SECRETARIA GERAL DA PRESIDÊNCIA DA CÂMARA DOS DEPUTADOS (Org.). Documentos pontifícios sobre questões sociais. Brasília: Imprensa Nacional, 1967.

MACHADO, Paulo Affonso Leme. Direito Ambiental Brasileiro. 12. ed. São Paulo: Malheiros, 2004.

MARTINS, Margarida Salema D'Oliveira. O princípio da subsidiariedade em perspectiva jurídico-política. Coimbra: Coimbra Editora, 2003.

MOTA, Mauricio Jorge P.; PEREIRA, Daniel Queiroz; PEREIRA, Vítor Pimentel. Direito ambiental das cidades: novas perspectivas acerca da sustentabilidade das regiões urbanas. Revista de Direito da Cidade, Rio de Janeiro, ano 1, n. ${ }^{\circ}$ 3, nov. 2007.

PIO XI. Carta Encíclica Quadragesimo Anno, de 15 de maio de 1931. In: SECRETARIA GERAL DA PRESIDÊNCIA DA CÂMARA DOS DEPUTADOS (Org.). Documentos pontifícios sobre questões sociais. Brasília: Imprensa Nacional, 1967.

PONTIFÍCIO CONSELHO JUSTIÇA E PAZ. Compêndio da doutrina social da Igreja. Tradução da CNBB. São Paulo: Paulinas, 2005.

QUADROS, Fausto de. O princípio da subsidiariedade no direito comunitário após o Tratado da União Europeia. Coimbra: Almedina, 1995.

SARAIVA, F. R. DOS SANTOS. Novíssimo dicionário latino-português. 9. ed. Rio de Janeiro: Garnier, 1927.

SILVA, Vicente Gomes da. Legislação ambiental comentada. 3. ed. Belo Horizonte: Fórum, 2006.

TORRES, Silvia Faber. O princípio da subsidiariedade no direito público contemporâneo. Rio de Janeiro: Renovar, 2001.

VAN ACKER, Francisco Thomaz. Breves considerações sobre a Resolução 237, de 19.12.1997, do CONAMA, que estabelece critérios para o licenciamento ambiental. Revista de Direito Ambiental, São Paulo, v. 2, nº. 8, out./dez. 1997.

VILHENA, Maria do Rosário. O princípio da subsidiariedade no direito comunitário. Coimbra: Almedina, 2002. 
ZAMPETTI, Pier Luigi. La familia y el estado social y participativo: un nuevo modelo de desarollo. Buenos Aires: Catálogos, 1997.

ZILIOLI, Chiara. L'applicazione del principio di sussidiarietà nel diritto comunitario dell'ambiente. Rivista Giuridica dell'Ambiente, Milano, fasc. 3-4, 1995. 